\title{
Comparative Analysis of Controller tuning Techniques of Ziegler Nichols and Genetic Algorithm in a Brushless Direct Current Motor
}

\author{
Aborisade David \\ Adebayo Isaiah \\ Dept. of Electronic and Electrical Engineering \\ Ladoke Akintola University of Technology, Ogbomosho \\ Nigeria. \\ Olugbemi Adetayo \\ Dept. of Electrical Engineering \\ Moshood Abiola Polytechnic, Abeokuta \\ Nigeria.
}

\begin{abstract}
:
The failure of conventional tuning method to obtain optimum performance in brushless direct current motor $(B L D C)$ is a great challenge in industrial control as this may result in time delay and difficulties in parameter variations. Although, the use of conventional tuning techniques had been considered suitable in controlling the speed and torque of a BLDC motor, however, these fails to perform satisfactorily in certain conditions especially, when considering the non-linear nature of the motor. Also, using conventional technique to tune the parameters gain of the Proportional Integral Derivative (PID) controller is a difficult task. To overcome these difficulties, modern heuristic optimization technique are required to optimally tune the PID of the controller for optimal speed and torque control of three phase BLDC motor. The Brushless DC Motor mathematical equation which describes the voltage and corresponding rotational angular speed and torque of the brushless DC motor was derived using electrical DC Machines theorem. The simulation of BLDC model based on GA-PID controller was done using $M A T L A B$ 2018a. The simulation result showed that by applying genetic optimization function, there are no transient oscillation in the system response.
\end{abstract}

Keywords: Brushless Direct Current motor, Speed/Torque control, Genetic algorithm, PID controller.

\section{Introduction}

Brushless DC (BLDC) motor is widely used in many industrial applications such as electric cranes, electric vehicle and robotic manipulator due to its numerous advantages over other conventional method such as better speed and torque characteristics, better dynamic response, high efficiency, no noise operation and high weight to torque ratio [1]. BLDC motor comes in single phase, two phase and three phase configurations. However, single and three phase are the most popular and widely used in many applications [2]. BLDC motor is an electronically commutated motor, having no brushes for commutation. The stator magnet which is usually made of steel sheet, the stator phase windings are inserted in slots or wound on the pole [3]. The emf produced by the BLDC motor is trapezoidal in shape which allow rectangular shape voltage to produce low ripples torque [4].So in this respect BLDC motor is behaving like the inverted dc commutator motor in which magnet rotate and conductors remain stationary [5]. In commutator dc motor brushes are used to reverse the polarity of current but in case of BLDC motor reversal is done using semi conductor switches [6], [7]

BLDC motor drives are driven by dc voltage, the DC bus voltage was connected across the active phases of the three phase winding of the motor and as the synchronized with the amplitude of the applied voltage, the amplitude of the applied voltage is to be adjusted by the duty cycle of the Pulse Width Modulation (PWM) signal used in controlling the six- switch inverter bridge, and thus continuously rotate the motor [8]. In order to maintain the constant revolution speed, regardless of the load, Proportional Integral derivative (PID) speed control strategies have been implemented [9]. A PID controller calculate an error value as the difference between measured process variable and a desired set point. The controller attempts to minimize the error by adjusting the process control input [10]. When the PID controller is used for controlling the BLDC motor, tuning is important. Many methods are available for tuning the PID controller, but the conventionally tuned PID controller does not provide optimum performance under nonlinear conditions and parameter variations [11]. GA control technique has been chosen due to improved robustness over the conventional linear control algorithms, simplified control design for difficult system models and simplified implementation [12]. 
The author of [13]proposed PID parameter optimization by Genetic algorithm, the work showed that GA method gives the smallest value of all performance indices for all range of time delay. There are convergence problem that arise in applying GA which was not experimented. Also, authors of [14] presented optimal of PID controller parameters on a DC motor based on advanced particle swarm optimization algorithm. The proposed method has fast searching speed compared to standard PSO. Furthermore, this method accelerates the convergence.

Comparative analysis of tuning a PID controller using intelligent methods was done in [15]. The controller tuned by the given methods has been used for concentration controls of a continuous stirred tank reactor (CSTR) but the process is difficult to apply in case of processes with large time delays. The main design criterion is related to disturbance rejection but it can only be used for first order models including large processes delay as affirmed in [16]. System tolerant to external disturbances were also considered which showed that GA-PID controller has a quick response to input disturbances when compared to classical control systems design.

The remainders of this paper are organized as follows: Sections II and III give the design requirements and the mathematical modeling for the BLDC motor speed and torque control, respectively. Results and discussion are presented in section IV while section V concludes the work.

\section{Design Requirements and Assumptions}

Since the most basic requirement of a motor is that it should rotate at the desired speed, steady state error of the motor should be less than $1 \%$. The other performance requirement is that the motor must accelerate to its steady state speed as soon as it turns on. In this case, one would expect it to have a settling time of 2 seconds and overshoot less than 5\% [17]. The idea here is that as one spins up the load in clockwise direction, the coils on the rotor rotate in the magnetic field and as a result, as the angular velocity of the load increases then the voltage generated by the back e.m.f also increases to give BLDC motor top speed [18].

\section{Mathematical Modeling for BLDC Motor Speed and Torque Control}

The model employed in this research as presented in Figure 1 consists of a battery with voltage source $\mathrm{E}_{\mathrm{a}}$ through sockets which are model. The electric motor used consists of three components such as resistance $R_{a}$, inductance $\mathrm{L}_{\mathrm{a}}$ and voltage source $E_{a} . \mathrm{R}_{\mathrm{a}}$ represents the resistance of the electric coil in the motor, $\mathrm{L}_{\mathrm{a}}$ represents the inductance of the coil while $E_{b}$ voltage called back e.m.f (Electromotive force) [19].

Figure 1 Model of a BLDC

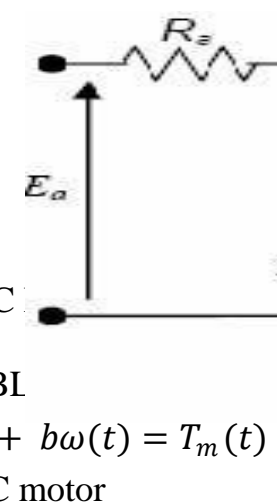

$$
\omega=\frac{d \omega}{d t}+b \omega(t)=T_{m}(t)
$$

The voltage loop of BLDC motor

$$
E_{a}(t)=R_{a} i_{a}(t)+L_{a} \frac{d i_{a(t)}}{d t}+E_{b}(t)
$$

Equations $(1,2)$ are combined to determine angular speed $\mathrm{w}(\mathrm{t})$ of the motor such that

$$
\frac{d \omega}{d t}(t)=\frac{K_{t}}{I_{L}} i_{a}(t)
$$

Transfer function of BLDC motor with load can be represented with $P_{(s)}$,

$$
P(s)=\frac{w_{(s)}}{E_{a(s)}}
$$

Combining Equations $(3,4)$ such that:

$$
E_{a}(s)=\frac{\omega_{(S)}}{E_{a(S)}}=\frac{1}{\left[S^{2} L_{a} \frac{I_{L}}{K_{t}}+S R_{a} \frac{I_{L}}{K_{t}}+K_{b}\right]}
$$

Substituting Equations (4) into (5), BLDC motor transfer function becomes:

$$
P(s)=\frac{\omega_{(S)}}{E_{a(S)}}=\frac{K_{t}}{\left[S^{2} J L+R J L+K_{b} K_{t}\right]}
$$

The response of BLDC motor to input signals such as impulse and step inputs can be verified using a model designed in SIMULINKS. 
The torque of a BLDC motor is relatively critical to its power and load functions. Torque control requires input variable as back e.m.f. and output variable as torque functions. Starting from first principle, the torque transfer function is derived from;

$$
\tau=F r
$$

From steady-state motor equations,

$\tau=K_{T} i_{a}-\tau_{f}, \quad e_{a}=i_{a} R_{a}+e_{b}, \quad e_{b}=K_{e} \omega_{m}, P=\omega_{m} \tau \quad$ and $\quad K_{e}=K_{i}$

Taking Laplace of both sides, the equation becomes;

$$
\tau(s)=\frac{s P \phi \omega(s)}{e_{a}-i R}
$$

Thus, the transfer function for the torque control is expressed as and represented as follows in Figure 3.2.

$$
\frac{\tau(s)}{\omega(s)}=\frac{s P \phi}{e_{a}-i R}
$$

For a closed-loop system, the transfer function becomes;

\section{System Model Parameters}

$$
G_{\tau}(s)=\frac{s P \phi}{P \phi s+\left(e_{a}-i R\right)}
$$

$\boldsymbol{\omega}=$ rotational angular velocity

$\mathrm{R}_{\mathrm{a}}=$ armature resistance

$\mathrm{L}_{\mathrm{a}}=$ armature inductance

$\mathrm{K}_{\mathrm{t}}=$ motor-torque constant

$\mathrm{K}_{\mathrm{b}}=$ back emf constant

$\mathrm{J}=$ moment of inertia of the motor

$\mathrm{I}_{\mathrm{L}}=$ moment of inertia of the load

$\dot{\omega}=$ angular acceleration

$\mathrm{b}=$ viscous friction coefficient of the motor

$\mathrm{T}_{\mathrm{m}}=$ the motor torque

$i_{a}=$ armature current

$\mathrm{E}_{\mathrm{a}}=$ armature voltage

$E_{b}=$ the back emf

\section{A. Implementing GA - PID for Speed Control}

Since the speed control transfer function has been developed, the control codes are configured on MATLAB software using the $\mathrm{C}++$ code. Figure 2 is the genetic algorithm tuned PID controller which will iterate the solver to achieve the best possible chromosome that will give the best $K_{p}, K_{i}$ and $K_{d}$ values to improve the system dynamic response characteristics. Figure 3 shows the flow chart for genetic algorithm implementation.

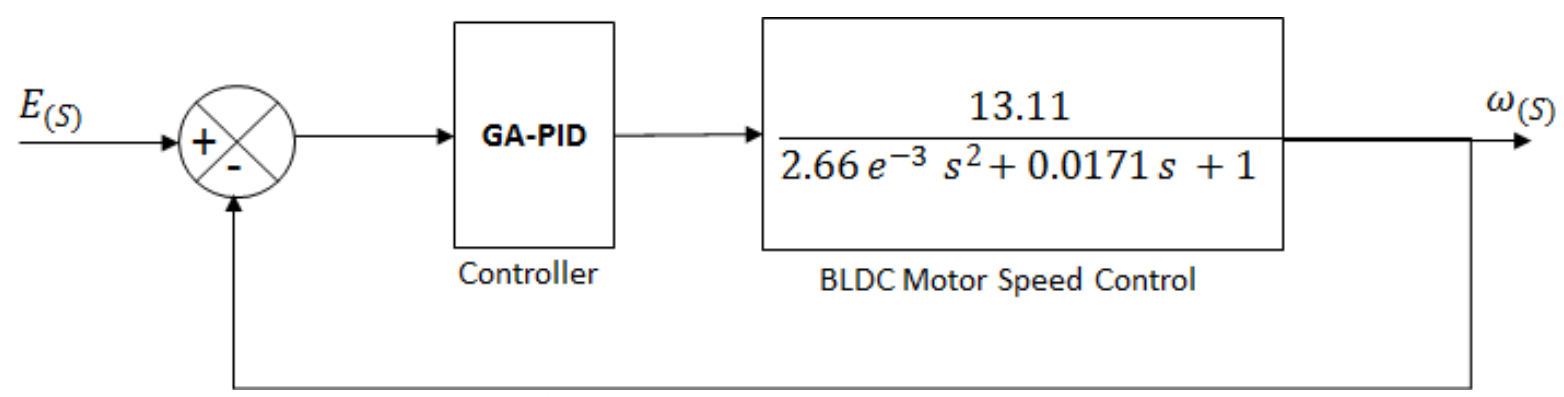

Figure 2: GA-PID controller application for BLDC motor speed control

\section{B. GA Controlled Speed and Torque System Model on MATLAB - SIMULINKS}

Simulink control design helps control systems designer to analyze and tune control systems modeled in Simulink, arbitrary controller architecture and linearization of modules to study modules behaviours around specific operating system can be achieved. A PID controller may be tuned with aid of PID tuners that automatically linearize models in Simulink, the PID gains can be calculated and responses can be easily plotted. Dynamic characteristics and the stability of the control system can be linearizing around operating points. Linear models can be examined in time and frequency domains and imported to MATLAB environment for simulation. Figure 4 display the model for Simulink control configuration for the combine speed and torque control. 


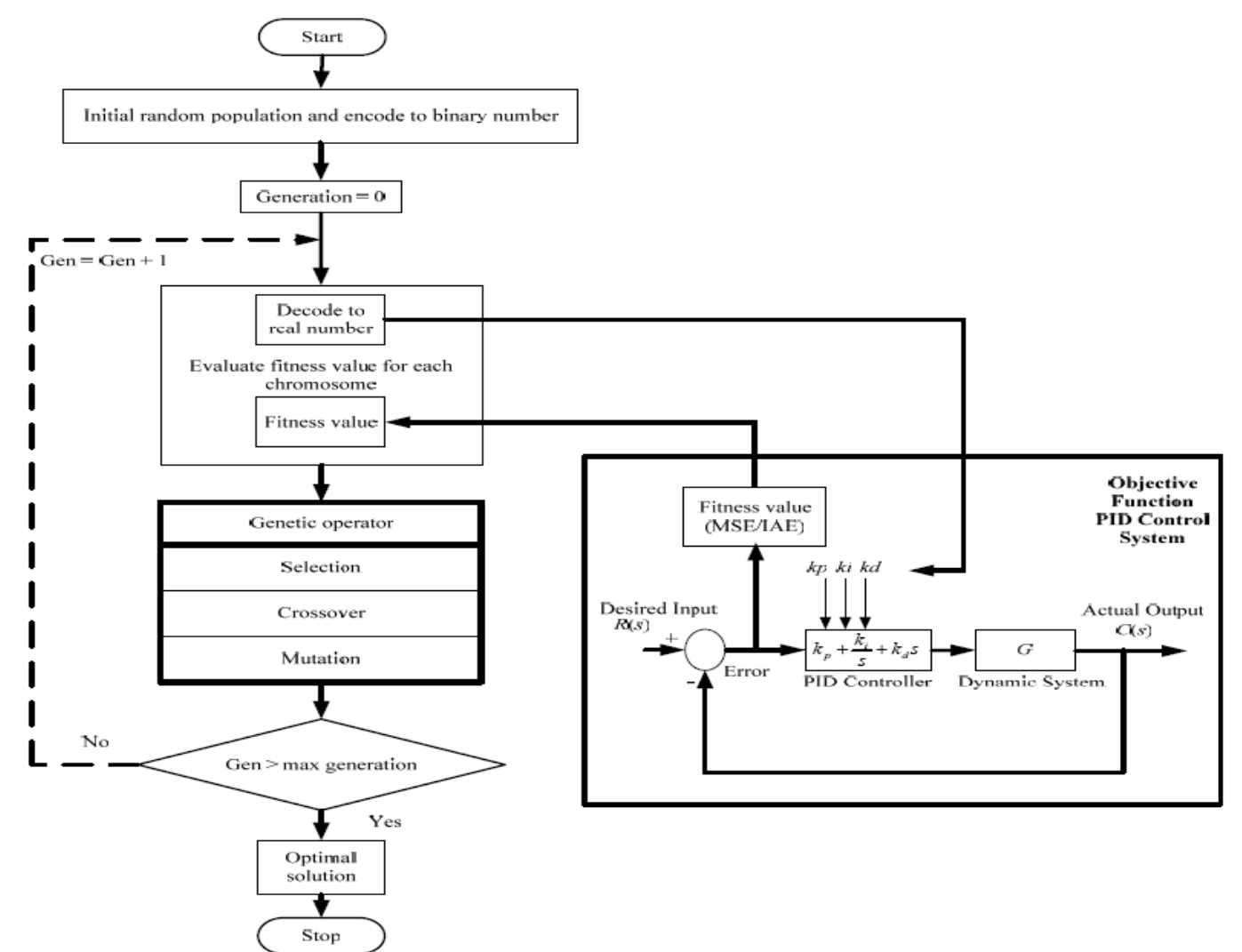

Figure 3: Proposed Flow chart of genetic algorithm implementation.

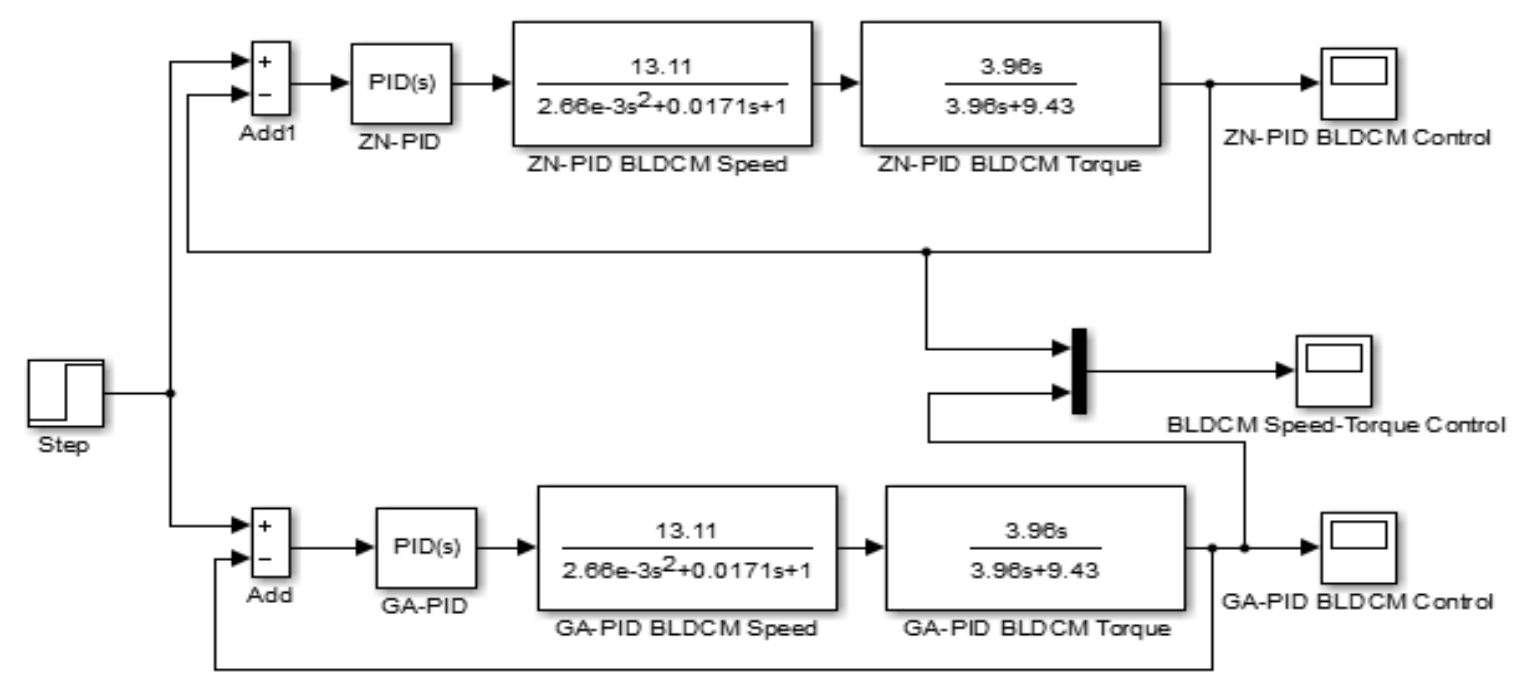

The simulation results from MATLAB software are explained first in steps then plots are compared for clarity of choosing genetic algorithm (GA) optimization method of tuning the proportional, integral and derivative (PID) controller. Figure 5 shows the response plot for Ziegler Nichols $(\mathrm{ZN})$ tuned PID controller configured with the nominal operating speed of $2860 \mathrm{rpm}$ and nominal operating torque of $58 \mathrm{mNm}$. The plot shows that the ZN- PID controlled system dynamic response is stable, with an overshoot of $21.44 \%$, a rise-time $\left(\mathrm{T}_{\mathrm{r}}\right)$ of $0.51 \mathrm{~s}$, settling time $\left(\mathrm{T}_{\mathrm{s}}\right)$ of 3.56s. 


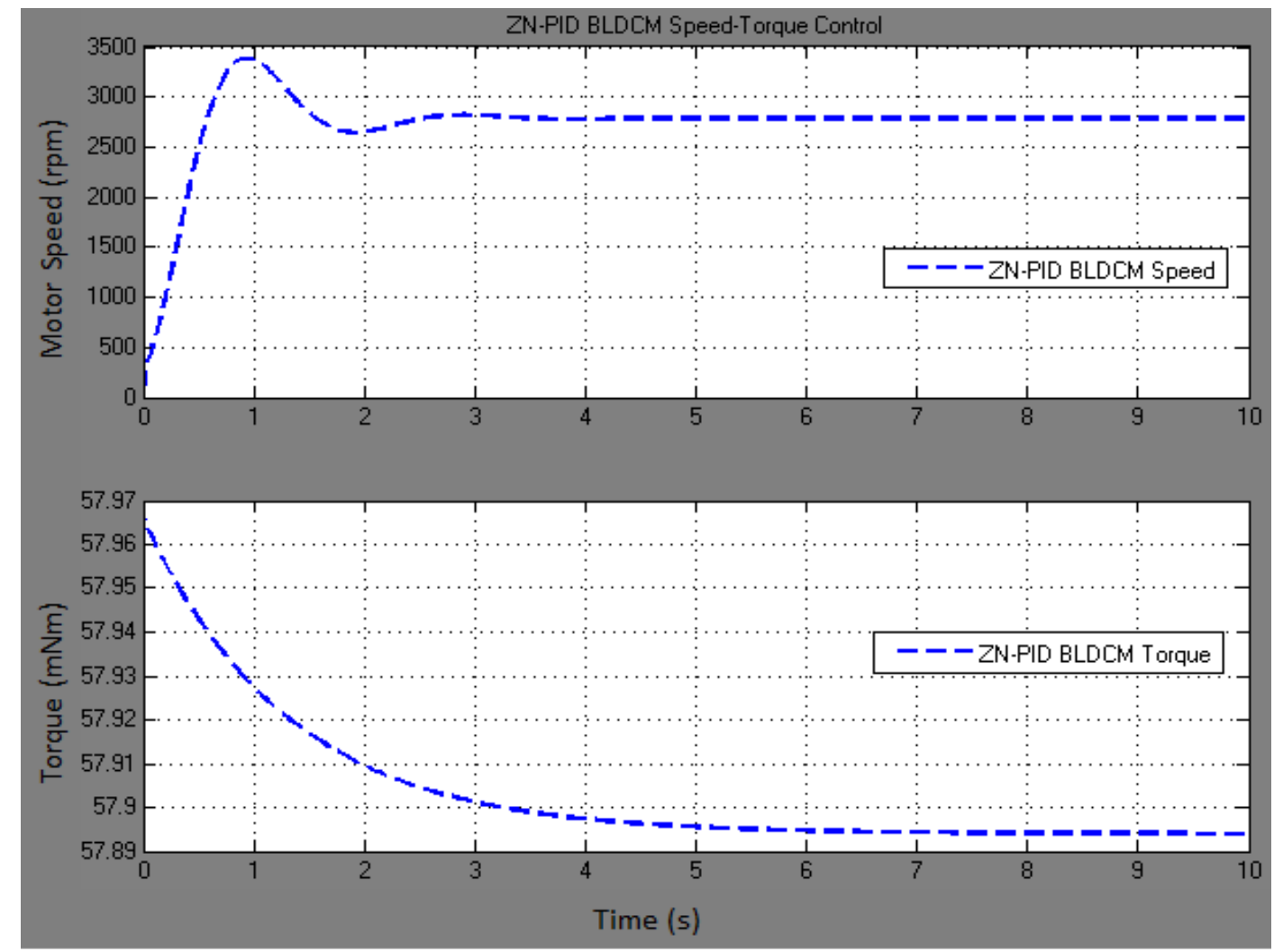

Figure 5 Step response for ZN-PID BLDC motor speed and torque control

The torque plot showed the varied relationship between the speed and the torque function. From first principle which connotes that as speed of the motor increases torque reduces. As the speed settles, the torque stabilizes. The final value for the torque is $57.895 \mathrm{Nm}$ against the configured nominal torque of $58 \mathrm{Nm}$. This experiment demonstrates the system dynamic resistance from back e.m.f. with torque tolerance of $\pm 0.105 \mathrm{Nm}$. Tolerance margin values are required in BLDC motor control due to varying degrees of speed values and system control variables.Figure 6 shows the genetic algorithm PID controlled system dynamic response plot for the BLDC motor. From the plot, it can easily be observed that overshoot is $0 \%$, rise-time $\left(\mathrm{T}_{\mathrm{r}}\right)$ is $0.65 \mathrm{~s}$, and settling time $\left(\mathrm{T}_{\mathrm{s}}\right)$ is $1.82 \mathrm{~s}$. It can also be deduced that there are no transient oscillations in the system response.

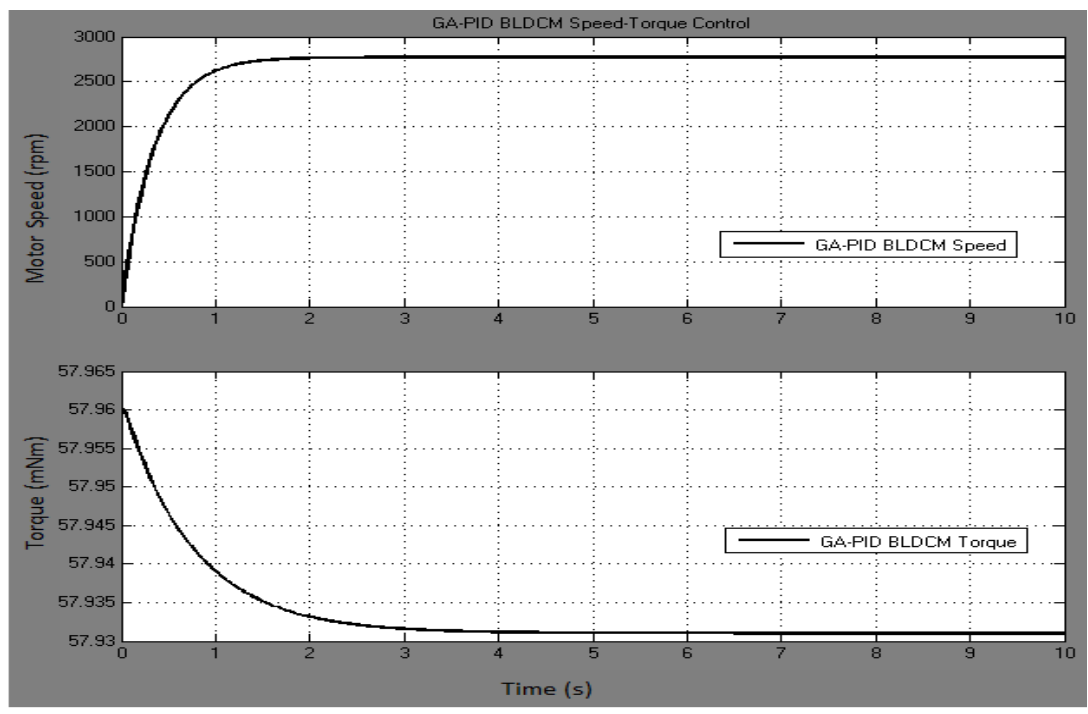

Figure 6 Step response for GA-PID BLDC motor speed and torque control

A comparison plot for both the ZN-PID and GA-PID controlled BLDC speed control is shown in Figure 6 and the dynamic system response characteristics is summarized in Table 1.The plots on Figure 7 showed that the system with GA-PID controller had the better system response when compared to the ZN-PID controller. Genetic algorithm tuned PID controller had exciting system response features for step input at nominal operating speed of 2860rpm. 


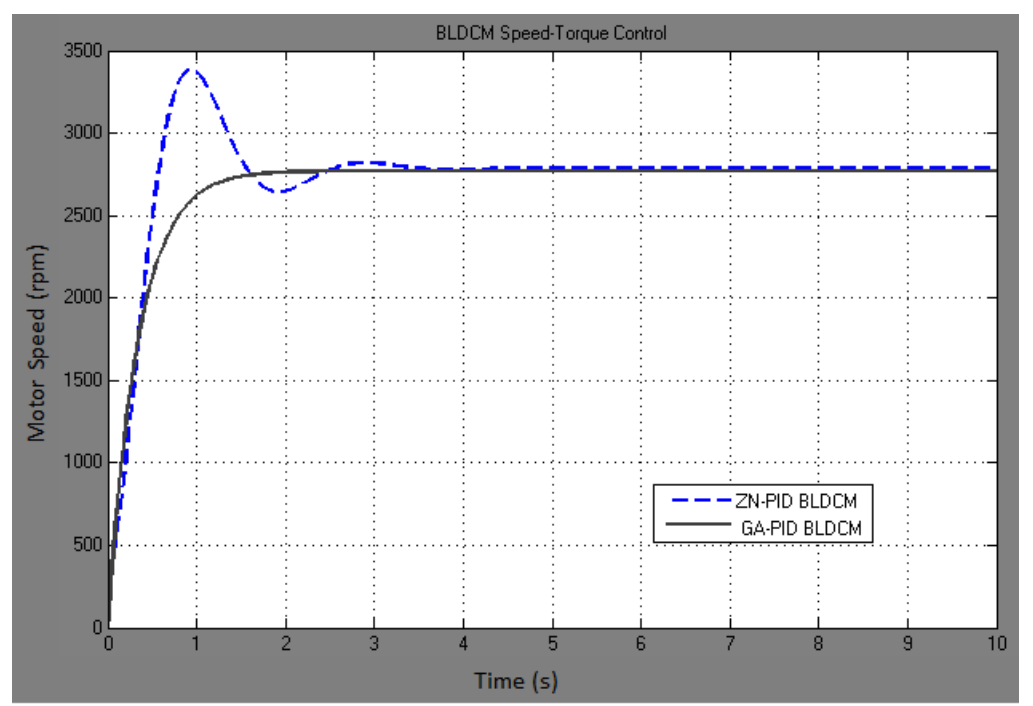

Figure 7: Comparison plots for both GA-PID and ZN-PID BLDC motor speed control

Table 1: Controlled system response characteristics for BLDC Motor control

\begin{tabular}{llll}
\hline Tuning technique & $\begin{array}{l}\text { Percentage } \\
\text { Overshoot }\end{array}$ & $\begin{array}{l}\text { Rise-Time }\left(\boldsymbol{T}_{\boldsymbol{r}}\right) \\
(\mathbf{s})\end{array}$ & $\begin{array}{l}\text { Settling Time }\left(\boldsymbol{T}_{\boldsymbol{s}}\right) \\
(\mathbf{s})\end{array}$ \\
\hline ZN-PID & 21.44 & 0.51 & 3.56 \\
GA-PID (ITAE) & 0.00 & 0.65 & 1.82 \\
\hline
\end{tabular}

\section{Conclusion}

Brushless direct current (BLDC) motor is a current major device widely used in modern industrial applications due to its control flexibility, discrete control and compactness. Therefore, it is imperative that speed and torque control is necessary in order to maintain a steady state performance with absolute values for both speed and torque. This ultimately enables the system to respond to transient or dynamic disturbances without overshoot and steady-state errors. The Ziegler-Nichols parameter for speed control presented an oscillating response plot when compared to the genetic algorithm optimization function which the later provided a better stable dynamic response plot.

\section{References}

[Mohd, F. and Mohd, N. 2006. Comparison between Ziegler Nichols and Cohen-coon method for controller tunings; Thesis report, University College of engineering college of engineering and technology.

Megha J, and Mohna, P. 2013. Speed Control of DC Motor Using Genetic

Algorithm Based PID Controller 3, Issue 7; International Journal of Advanced Research in Computer Science and Software Engineering

Brian, R.C. 2008. The Design of PID Controllers Using Ziegler Nichols Tuning. Maxon EC Motor, EC45 Flat ${ }^{\phi}$ 45mm, Brushless, 30watt Maxon Flat Motor.

Balogh, T, Viliam, F. and Frantisek, D., Modeling and Simulation of the BLDC Motor in MATLAB; proceeding of the IEEE Fifth International conference on Fuzzy Systems and Knowledge Discovery 1403-1407.

Atef, S.O. and Mashakbeh 2009. Proportional Integral and Derivative control of brushless DC motor; European journal of scientific research, Vol 35, 198-203.

Oguntoyinbo, O. J. 2009. PID control of Brushless DC Motor and Robot Trajectory Planning and Simulation with MATLAB.

Nihat, O. and Emre, C. 2012. Speed control of permanent magnet synchronous motors using fuzzy controller based on genetic algorithms; Electrical Power and Energy Systems 889-898.

Neenu, T. and Poongodi, P. 2009. Position Control of DC Motor Using Genetic Algorithm Based PID Controller.; Proceedings of the World Congress on Engineering II.

Rohit G. K. and Meshram, P.M. 2012. Optimal Tuning of PI Controller for Speed Control of SSDC motor drive using Particle Swarm Optimization; 978-1-4673-2043 IEEE

James, O. and Arazi, N. 2008. Modeling of Speed Control in a DC Motor using Proportional Integral and Derivative Controller; Int. Journal of Control, Vol 14, No 1.

Mahony, T.O.; Downing, C.J. and Fatla, K. 2000. Genetic Algorithm for PID Controller Optimization: Minimizing Error Criteria. Process Control and Instrumentation, University of Strachdyde, 148-153. 
Lasse, E. 2008. PID controller design and tuning in network control systems, Thesis report, department of automation and system technology, Helsinki University of technology.

Liufan, E. and Meng, J. 2009. Design for auto tuning PID controller based on Genetic Algorithm, ; IEEE conference on industrial electronics and applications.

Yaghoub, H., Abolfazl, R. N., Heydar, A. S., and Soheil, S. 2010. Robust Control of DC Motor Using Fuzzy Sliding Mode Control with Fractional PID Compensator; Journal of Mathematics and Computer Science, Vol1, No 4.

Vishal, V, Harish, and Renu, B. (2012). Hybrid PI Speed Controllers for Permanent Magnet Brushless DC Motor; 978-1-4673-09 IEEE

Walaa M., Elsrogy, M. A, Fkirin, M. A and Moustafa, H. (2009). Speed Control of DC Motor Using PID Controller Techniques Based on Artificial Intelligence

Wang, H. and Pengfi,L. (2010), Improving Speed control of BLDCM Through Full Adaptive Fuzzy Controllers; 978-1-424 IEEE. 